\section{Isostasy and flexure of the lithosphere}

\author{
by Anthony B. Watts
}

Cambridge University Press, 2001. Paperback 458pages, £29.95 (US\$44.95), ISBN 052100600 7; hardback 458 pages, $£ 75.00$ (US\$110.00), ISBN 0521622727.

Anthony Watts is one of the eminent workers in the study of flexure on the Earth and planets and has made a number of seminal studies in the field. With his new volume, Isostasy and Flexure of the Lithosphere (Cambridge University Press), Dr. Watts shares his expertise with readers in a book that is both readable and packed with information.

The strength of the book is in its extensive discussion of geological applications of elasticity (and visco-elasticity). Even the more theoretical chapters end with numerous practical examples.

The first chapter of the book provides a historical development of the concept of isostasy, beginning with the ideas of Leonardo da Vinci, and continuing through the work in the 1800's of Airy, Pratt, Fisher and Dutton. He lets the historical development continue to derivations of the equations for the Free Air, Bouguer, terrain and isostatic corrections for gravity.

The second chapter continues the historical approach, focussing on flexure and the debate between local versus regional compensation. It discusses the early work of G.K. Gilbert and leads us to the later pioneering work of Vening Meinesz and others. Watts takes great care to link these early developments to the plate tectonic revolution of the latter part of the 20th century. He revisits these linkages throughout the book.

With chapter 3, Watts discusses elastic plate theory, primarily relying on the discussion of deformation in beams. He justifies this restriction on the basis of geologically relevant geometries. The level of treatment here is similar to that of Geodynamics by Turcotte and Schubert (John Wiley and sons, 1982), thus appropriate for graduate students or advanced undergraduates. Toward the end of the chapter he provides a brief description of the deformation of circular plates. While the more advanced reader may have wished for a more complete development of the theory, Watts provides the necessary references. However, he should have defined the basis functions that he uses in the solution equation (3.54). To go further, Watts could have omitted his table of Hetenyi Functions (Table 3-2) and provided a figure showing the Kelvin-Bessel functions in equation 3-54.

At the end of chapter 3 the author discusses numerical techniques with a focus on the finite difference approach. I would have encouraged him to include a discussion of the finite element approach to solving the bihar-

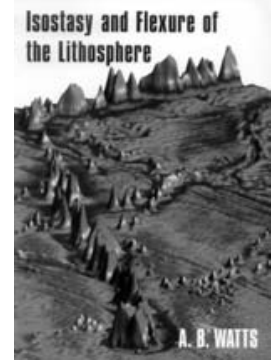

monic equations. It is the technique of choice for many workers in the field. Although a technical derivation of numerical techniques was beyond the scope or space available in the book, more discussion would have been useful.

Chapter 4 presents a wide variety of geological examples of flexural problems on the Earth. These include glacial rebound, trench and outer ridge deformation, and loading of the continental margin at river deltas. Of course, the very important work on seamounts and islands (much of it pioneered by Watts) is presented in wonderful detail.

With chapter 5, Watts develops the ideas of gravitational admittance and the lithosphere as a filter. He reexamines the Airy and Pratt models for isostatic balance in this light. While this was nicely done, the chapter would have been greatly improved by the extension to solutions of the two-dimensional Cartesian biharmonic equation. This is relatively simple to derive, and it would have been good to include it in this volume. For the reader interested in a practical tutorial, two-dimensional filter solutions are far more useful. As always, Watts ties his theoretical discussions to applications to Earth models. Particularly useful to the serious student will be his Table 5-2, an exhaustive listing of spectral studies on continents, extending up to 1999

Chapter 6 discusses rheological models for Earth behavior, as well as the nature of the elastic parameters including flexural rigidity, relaxation time, and elastic thickness. Particularly important is the discussion of the agedependence of these parameters for the ocean lithosphere. (A new student may be a bit disheartened to learn that there are at least 186 previous studies of elastic thickness in the ocean lithosphere.) Watts then discusses rheological models that may explain the characteristics of the data. The chapter is 62 pages long and is richly illustrated. Many of the important figures are reproduced in the color-plate section of the book.

Chapter 7 is by far the longest of the chapters, and it is an extensive discussion of flexural-isostatic response of the loading on plate boundaries and interiors. There is extensive discussion of rifting, compressional tectonics, strike-slip tectonics, and intraplate deformation. All of the discussion is up-todate (1999) and easily presented.

The final chapter discusses isostasy on planets. While its treatment of each of the terrestrial planets is necessarily brief, Watts presents a very useful introduction to this fascinating topic.

The book includes some 28 pages of references, and it will be easy for the reader to extend his or her knowledge beyond the coverage in this book. As such, the book is also a valuable reference, as well as an excellent introduction. I believe that the subject index could have been more thorough.

Isostasy and Flexure of the Lithosphere provides a very thorough discussion of the myriad applications of gravity and visco-elastic theories to geological problems. The strength of the book is its breadth of coverage on this fascinating topic. Dr. Watts provides the reader with outstanding background on just about any topic or problem she or he might want to solve. As in all books, the author had to make omissions; here he left much of the details of the mathematical development to previous authors. However he provides necessary references. My only criticism in his selection of mathematics is that he could have included a more thorough discussion of twodimensional solutions, including the all-invasive numerical techniques.

In summary, I found this book to be readable, and very useful. At a price of GPB 30 (less than \$45), it is an absolute bargain. Graduate students, advanced undergraduates and professionals will enjoy this volume and find it very useful in future work.

\section{Prof. James S. McClain}

Department of Geology, One Shields Ave., University of California,

Davis, CA 95616

USA

\section{The techniques of modern structural geology Volume 3: Applications of continuum mechanics in structural geology}

\section{Ramsay, J.G. and Lisle, R.J.}

Academic Press, London, 2000. Paperback, pp.701-1061. US Price: \$65.00. ISBN 012 576923-7.

What should students of structural geology know? The answer depends upon the student. For undergraduate students it is generally expected that they should be able to (1) recognize, describe and provide at least a rudimentary interpretation of basic geological structures, (2) create and interpret a geological map, and (3) construct cross-sections. For graduate students and researchers we expect more. Specifically, that they should be capable of (1) rigorous quantitative analysis of deformed rocks, (2) modeling of the processes involved in the deformation of rocks, and (3) placing deformation within a plate tectonic framework.

Available textbooks take aims at different levels within this broad continuum. The three volumes that together comprise "The Techniques of Modern Structural Geology", 


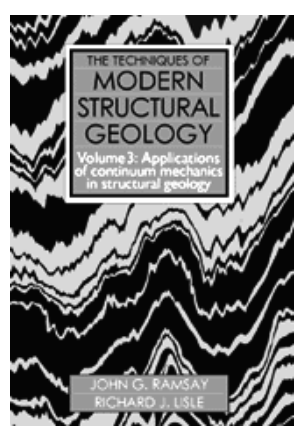

all published by Academic Press, are clearly aimed at the upper end of this spectrum. Nonetheless, Volumes 1 and 2, though dense, have proved sufficiently versatile and well written that they have been adopted by numerous lecturers as textbooks for undergraduate classes. My suspicion is that Volume 3 (Applications of continuum mechanics in structural geology) will turn out to be somewhat less versatile, and therefore of less appeal to undergraduate students, it being far more mathematical than the previous two volumes. That said, Volume 3 is no less well written. In addition, it is wonderfully illustrated, and the rewards of working through many worked examples provided throughout the volume are more than worth the pain of having to come to grips with the math.

In Volume 1 of this series, Strain Analysis, published in 1984, Ramsay and Huber sought to teach how to quantify and analyze strain. The overwhelming success of that book is indicated by how, since its publication, the measurement and analysis of strain has become such a routine aspect of structural geology.

In the second volume (Folds and Fractures), published in 1987, Ramsay and Huber dealt with the main goal of structural geology that is to recognize, describe and interpret basic structures (folds, faults and fractures). The enormous success of these two volumes is based on the eloquent and straightforward prose employed by the authors, the beautiful and appropriate illustrations (both line drawings and excellent plates of natural structures), and on the problem based approach the authors guide you through a series of increasingly difficult, but always fun, worked problems.

The strength of Volume 3 is that Ramsay and Lisle have stuck to the recipe that made Volumes 1 and 2 so successful. Once again we are treated to a beautifully illustrated book, with numerous pictures and line drawings of natural structures. The importance of providing so many natural examples in a book so rooted in mathematical analysis cannot be understated throughout the text Ramsay and Lisle go to great lengths to demonstrate how mathematical analysis relates back to structures described in the field.

Once again the book proceeds through an increasingly challenging set of worked problems: this is a hand on book that cannot be simply read, it has to be worked. And once again the prose is elegant, succinct and straightforward. The book progresses logically and coherently forward through an introduction to heterogeneous stress. Clearly the authors attribute the distribution of structures through a body of rock to variation in the principal stress directions. This can be debated, but it does provide an effective means of analyzing heterogeneously deformed rock bodies at all scales. Then, through chapters on modeling and finite element analysis, the reader is dropped into the mathematical methods of analyzing heterogeneously deformed rocks. While these chapters are heavy on math, they are well illustrated and benefit enormously from the inclusion of worked examples. The payoff is in the application. The reader is subsequently guided through chapters on fault slip analysis, heterogeneous strain in shear zones, multiply deformed rocks, folds, and ductile flow.

If I were to have a complaint about this book, it would be its unnecessary promotion of jargon. We learn of "Couette flow", and "P bands", and "Griffith cracks" and "Trineau Ècraseur" and on and on. There is simply too much jargon in structural geology, and much of it without any good reason for existing. How many times must we listen to talks in which half the audience is left in the dark simply because they had no idea that the "Pbands" continually referred to by the speaker were nothing more than pressure solution bands. There is more than an enough in this book for even the most ardent fan of continuum mechanics. When I see my undergraduate students struggling to comprehend a stereonet, I have to conclude that this book would be beyond the ken of most of them. And, going back to my opening statement, the mathematical approach put forward in this book is beyond what we need expect of undergraduate students. There are only so many hours of instruction in a single term, and this book alone could be the basis for an entire semester of work. That said, any student would benefit from reading through the introductory sessions to each chapter, working through at least some of the problems presented here, and studying the fabulous examples of structures present through out the book. However, the main audience for this book will be those graduate students and researchers actively involved in detailed research of structural geology.

\section{Stephen T. Johnston}

School of Earth \& Ocean Sciences

University of Victoria

Victoria, $B C$

CANADA

\section{Seismic ray theory}

\section{by Vlatislav Červeny}

Cambridge University Press, 2001. Hardback 714pp. $£ 90.00$ (US\$130.00). ISBN 0521366712.

When a thin light beam propagates through air with suspended dust particles, the light beam shows up as a luminescent line through space. Historically this gave rise to the notion of light rays. The analogy with propagating particles made this a natural starting point for the theory of optics. This description of light turned out to be incomplete, as it does not account for wave properties of light such as diffraction. Nevertheless, ray theory remains a corner stone in the field of optics, as it is a correct asymptotic description of light propagation in the high-frequency limit.

Not surprisingly, ray theory is of great importance in seismology as well since it accounts for a simplified description of the propagation of elastic waves. This description is valid in the limit of high frequencies and finds application both in global seismology as well as in exploration seismology. In this book Vlatislav Cervený gives a comprehensive description of ray theory for elastic waves.

First, the general principles of elastic waves are treated. Throughout the book the treatment includes the simplest case of acoustic waves, the more complex case of elastic waves in isotropic media, and the hardest case of elastic waves in anisotropic media. The book proceeds with the treatment of seismic rays and travel times. The connection with the Hamiltonian and Lagrangian formulation of mechanics is made and the theory is presented in different coordinate systems. Paraxial rays are described in the next chapter, again using a variety of different coordinate systems including ray-centered coordinates. The paraxial rays are then used to treat amplitudes, geometrical spreading and phase shifts due to the KMAH index. This material includes the imprint of discontinuities on amplitudes and Gaussian beams. The book ends with a chapter on synthetic seismograms and appendices with the Fourier and Hilbert transforms.

This presentation of the material is dense; this is a book for the hardy reader interested in the details of seismic ray theory. To a large extent this is unavoidable; ray theory for elastic waves is a difficult topic where the clutter of tensor algebra tends to hide the underlying physics for many readers. In this book no numerical examples of the theory are shown because these would make the book grow further beyond its present size of 713 pages. A website is provided where the reader can view numerical examples that illustrate the theory. Overall, the author did a great job in making the material not more complex that it has to be. His consistent nota- 


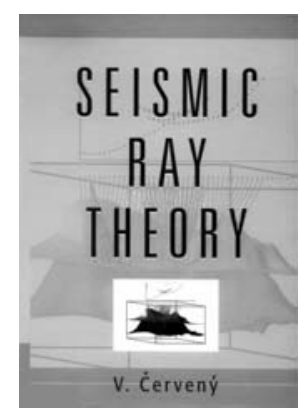

tion and deep physical insight make this into one of the most accessible sources on seismic ray theory.

This is the most comprehensive book on seismic ray theory that has ever been written. Its completeness lies not only in the material that is presented. The reference list with about 1000 references provides a comprehensive overview of the work on seismic ray theory as it has been developed in the second half of the past century. This reference list does justice to a large variety of research groups and includes many original publications in Russian that formed the foundation of seismic ray theory.

Sometimes the time is just right for something to happen. This is certainly the case for this book that will go in history as a seminal work on seismic ray theory. It is fitting that such a book is published at the turn of the century.

\section{Roel Snieder}

Center for Wave Phenomena,

Colorado School of Mines,

Golden CO 80401,

USA

\section{Geology of Egypt and Libya}

by Tawadros, E.E.

A.A.Balkema Publishers, 2001. $25 \mathrm{~cm}$, 480 pp.. EUR 95,00 / \$ 95,00. ISBN: 905809 $331 \mathrm{X}$.

There are many different approaches to writing a book that describes the geology of a particular region or specific country. Some authors will aim to write an introductory account, perhaps copiously illustrated, intended to introduce students and the interested layman to the subject in a way that will hopefully stimulate them to build on this first gained knowledge and pursue the subject further. At the other end of the spectrum, the aim may be to write a scholarly work of reference, crammed with detail, designed for the serious researcher whose expectations differ radically from those of a new student or casual "geotourist". The book reviewed here definitely belongs to the latter category.

Egypt and Libya together occupy a substantial part of northeast Africa, their combined area amounting to almost three million square kilometres. It is understandable, therefore, that such an extensive tract of geology requires an extensive tract of text to adequately describe and synthesise the current state of knowledge of that geology. This is what exactly Edward Tawadros offers us in his book. It comprises over four hundred pages of densely packed text, supplemented by some forty figures and twenty two tables, an impressive list of over two thousand references and a subject index of over one thousand five hundred entries. All of this, taken together, aptly indicates the scope of this volume and the serious intent of its author.

Such a wealth of information in a single volume requires careful organisation if it is not to discourage all but the most dedicated and determined reader from discovering the information that he or she seeks. Obviously much careful thought has gone into this problem of organisation and as a result the book is divided into five parts. The first part introduces a tectonic framework for Egypt and Libya and discusses the main tectonic elements comprising this framework. The second part is concerned with the geology of the Nubian-African Shield which evolved during Precambran and Early Cambrian times. The third and fourth parts respectively deal with the Phanerozoic stratigraphy of Egypt and of Libya, while the fifth part, building on the earlier sections, provides a synthesis of the geological evolution of the two countries and discusses this in the context of global tectonics and attendant sea-level fluctuations. A sixth part is the list of over two thousand references.

In the preface to the book the author notes that recent research in Egypt and Libya "has resulted in a flood of new nomenclature, much which seemed unnecessary". Many of us will recognise this problem born of the apparently insatiable, and ill disciplined, desire of researchers to erect new lithostratigraphic units and subdivisions of units within their research areas regardless of the utility or historic precedence of previous schemes. With this in mind, one cannot but admire the author's dedication in attempting the enormous task of guiding the reader through the maze of stratigraphic terminology that much of the "unnecessary" new nomenclature has created. Many of the tables and schematic figures in the book are new compilations by the author aimed at assisting in this task. I believe this will be seen as one of the great strengths of this book and an enduring contribution to future researchers in the region.

There are very few illustrations in this book other than the forty or so "schematic" figures and this fact adds to the somewhat daunting appearance of the four hundred pages of text. However, there appears to have been great attention to detail and this reader noted very few misprints and welcomed the fact that all measurements were quoted in both metric and imperial units. I am not an expert on the geology of this part of the world but if I aspired to being such I would probably find this book essential reading. Certainly it should find its way on to the

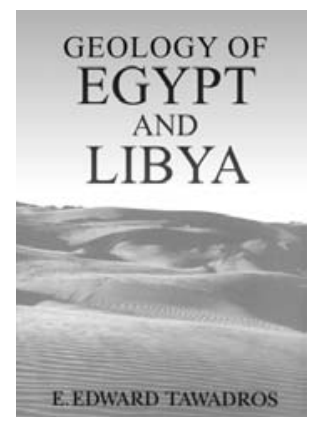

shelves of the geology section of every reference library both within the region and elsewhere whilst those professionals delving more deeply into the geology of north-east Africa will want a copy in their own collection.

\section{A J Reedman}

Honorary Research Associate, British Geological Survey

Keyworth,

Nottingham NG12 5GG

$U K$
Please contact us for rate and schedule information.

Tel: $\quad+86-10-68320827$ +86-10-6832 9084

Fax: +86-10-6832 8928

E-mail:

episodes@public2.bta.net.cn 